\title{
Relationship between chronic periodontal condition and metabolic syndrome among community-dwelling elderly in Yogyakarta, Indonesia
}

\author{
Elastria Widita ${ }^{1}$, Lisdrianto Hanindriyo ${ }^{2}$, Bambang Priyono ${ }^{2}$, Iffah Mardiyah ${ }^{1}$, Fimma Naritasari ${ }^{3}$, \\ Dewi Agustina $^{3}$ \\ ${ }^{1}$ Dental Hygiene Division, Faculty of Dentistry, Universitas Gadjah Mada, Indonesia \\ ${ }^{2}$ Department of Preventive Dentistry and Dental Public Health, Faculty of Dentistry, Universitas Gadjah Mada, Indonesia \\ ${ }^{3}$ Department of Oral Medicine, Faculty of Dentistry, Universitas Gadjah Mada, Indonesia
}

Objectives: Metabolic syndrome (MetS), a cluster of three or more risk factors of cardiovascular disease, is associated with periodontal disease. This study examined the relationship between chronic periodontal condition and MetS.

Methods: A cross-sectional study was conducted with 122 community-dwelling elderly aged $\geq 60$ years living in Yogyakarta, Indonesia who underwent full-mouth periodontal examination. The association was evaluated considering the number of sites of probing pocket depth (PPD) $\geq 6 \mathrm{~mm}$ and clinical attachment level (CAL) $\geq 9 \mathrm{~mm}$ as clinical parameter for chronic periodontal conditions. Five components (obesity, high blood pressure, low-high density lipoprotein cholesterol, hypertriglyceridemia, $\mathrm{HbA1c}$ ) of MetS were evaluated. Individuals with $\geq 3$ positive components were defined as having MetS. The relationship between chronic periodontal conditions and MetS was determined by logistic regression analysis with adjustment for smoking, gender, age, number of teeth, and hsCRP.

Results: Overall, 28 individuals (23\%) were diagnosed as having MetS. Probing pocket depth and CAL were analysed separately in multivariate models. Clinical attachment level was significantly associated with MetS (odds ratio $[\mathrm{OR}]=1.16 ; 95 \%$ confidence interval $[\mathrm{CI}]=1.05-1.28)$.

Conclusion: The results of this study suggest that chronic periodontal condition indicated by CAL $\geq 9 \mathrm{~mm}$ is significantly associated with MetS among the elderly.

Keywords: probing pocket depth, clinical attachment level, metabolic syndrome, elderly

Copyright (C) 2021. Korean Academy of Preventive Dentistry. All rights reserved.

This is an Open Access article distributed under the terms of the Creative Commons Attribution Non-Commercial License (http://creativecommons.org/licenses/ by-nc/4.0) which permits unrestricted non-commercial use, distribution, and reproduction in any medium, provided the original work is properly cited. 